environmental quality should be set at a level which is inconsistent with two other Commission Directives, unjustified on grounds of safety to human beings or wildlife, and below the limits detectable by routine analyses. As one of our witnesses put it, data appeared to have been plucked out of the air using a concentration factor much higher than the one thought to be reasonable by British experts.

We all want to reach amicable agreement with the Commission over an environmental policy for the Community, and we all agree that dieldrin is a harmful substance which ought be phased out as soon as satisfactory alternatives are found. But we see no prospect of amicable agreement unless the Commission can be persuaded to adopt two simple principles when it prepares its Directives.

- The first principle is to abide by a declaration of the Council of Ministers made in 1973 about the environment. This declaration is the only authority for having a European environmental policy at all. It states that protection of the environment should be achieved "at the lowest cost to the Community" and that in setting quality objectives "proper account must be taken of the specific characteristics of the regions in question"'.

This means the deployment of our limited resources in places where they could be most cost-effective. It means that we should have different environmental qualities for rivers, depending on whether they carry game fish, coarse fish or no fish at all. Following this policy in Britain over the last 20 years, we have increased the amount of unpolluted rivers by about 4,500 kilometres and we have diminished the amount of badly polluted rivers by about 1,500 kilometres. I doubt whether any other member state in the Community can match that record. A doctrinaire pursuit of uniform emission standards would wreck this policy.

-The second principle is to insist on free and candid disclosure of the scientific evidence on which Directives are based. It simply is not good enough for the Commission to say, "After consulting a group of experts, we set such and such standards"'. The Select Committee has now got plenty of evidence that the experts' advice is not always taken. To comply with some of these Directives - for instance, that proposed for fish - would put member states to enormous expense and to expect them to incur this enormous expense without even seeing the data on which the standards are based is, I suggest, an intolerable situation. I am afraid it is true - and we regret it - that there will be perpetual wrangling over environmental policy in the Community until this freedom of information is secured.

Compared with the Common Agricultural Policy, the Commission's environmental policy for Europe may well be a small matter. But it is a perpetual source of irritation.

\title{
UK to tighten asbestos controls
}

TIGHTER safety standards for asbestos are proposed in a report published last week by the UK Health and Safety Commission (HSC). The report, prepared by the commission's Advisory Commission of Asbestos (ACA) makes proposals, which according to the committee's chairman $\mathrm{Mr}$ Bill Simpson would, if they became law, "mean that Britain would share with Sweden the most stringent asbestos rules of any country".

The report recommends that the standards currently in operation regulating asbestos fibre concentration should be halved to $1 \mathrm{fb} \mathrm{ml}^{-1}$ for chrysotile (white asbestos); reduced four-fold to $0.5 \mathrm{fb} \mathrm{ml}^{-1}$ for amosite (brown); and that a statutory ban be placed on crocidolite (blue) in the UK. In addition, until such fibres as crocidolite are replaced, the standard for its removal should remain at the present 0.2 $\mathrm{fb} \mathrm{ml}^{-1}$.

It is proposed that the new standards should take effect from 1 December 1980 and that in future they should be referred to as "control limits" rather than "hygiene standards", the latter definition suggesting an asbestos concentration below which exposure is safe.

Simpson firmly believes that the new standards will reduce the incidents of asbestos-related diseases in future. It is the report's view that exposure to one fibre per mille of chrysotile daily over a period of 50 years will cause an increased mortality rate of 0.02 to 1.25 per cent. This prediction is based on the results of the only three surveys - two North American, one British - which provided adequate dose/response data. Calculations of mortality rates based on these results have th sir problems, however, as the report readily admits. Much of the data in these surveys on asbestos concentration was obtained by measuring particle counts, a far less precise method than the normal practice of counting fibres.

As far as the public is concerned, the report concludes that there is no quantitative evidence of risk from overexposure to asbestos dust. The report says that despite the fact that there is a high proportion of individuals, especially in urban areas, with asbestos fibres in their lungs, there has been no general reporting of asbestosis. Accordingly the report suggests that "there may be a threshold level" below which asbestosis is not detectable.

This, however, does not hold true for the carcinogenic properties of asbestos. The report states baldly that there is "no evidence" for the existence of a threshold below which lung cancer or mesothelioma - of the pleura or the peritoneum - will not occur. It is the report's view, however, that crocidolite is consistantly more dangerous than chrysotile and should be treated accordingly. Swedish and Dutch regulatory authorities agree.

The report acknowledges that all forms of asbestos will cause lung cancer. In numerical terms, lung cancer is the great killer but the report says "included in this excess mortality from lung cancer is a substantial element due to the syenergistic action of tobacco with asbestos, which cannot therefore properly be attibuted to the effect of asbestos alone"'. The asbestos industry has always made much of this synergism to play down the role of asbestos in the aetiology of lung cancer.

On the quesion of death due to mesothelioma, the report is unequivocal; the majority of these are due to exposure by chrysotile. Death from mesothelioma reported in American asbestos workers (the report says) are attibutable to exposure to both amosite and chrysotile and not to chrysotile alone.

Deaths from mesothelioma in the UK doubled between 1967 and 1976 currently standing at some 320 per annum - and the report expects the number to increase before the peak is reached.

The asbestos industry makes no pretence of being pleased about the December 1980 deadline for enforcing the 0.5 fibre per mille limit for amosite. Mr S D Hardie of Turner and Newall and an advisory committee member says that the deadline is too tight. He insists that working to 0.5 fibres per mille is pushing the technology to its limit. The industry, he says, can work to one fibre per mille of chrysotile but, as far as the 0.5 fibre per mille for amosite is concerned, Hardie says he could not "put his hand on his heart and say to the work force that it is not being exceeded"'.

Criticism that the advisory committee has been too sensitive to the needs of industry has been voiced by the Society for the Prevention of Asbestos and Industrial Diseases. Mr Max Madden, a trustee of the society and former Labour MP for Sowerby - a constituency which includes the ACRE Mill asbestos factory at Hebden Bridge - was frank about the pressure on the advisory committee. In his view, the committee had been subjected to considerable propaganda from the industry and some of it had succeeded. Anticipating criticism of its report, ACA chairman Bill Simpson emphasised that the control limits are not a "once and for all" exercise. New evidence will be constantly reviewed, and every encouragement was being given to the development of safe asbestos substitutes.

Comments on the report are invited and should be submitted by 31 January 1980 .

Alastair Hay

Asbestos Volume 1, final report of the Advisory Committee, $£ 5(p+p)$.

Volume 2, papers prepared by the Advisory Committee $f 5(p+p)$ available from HMSO. 